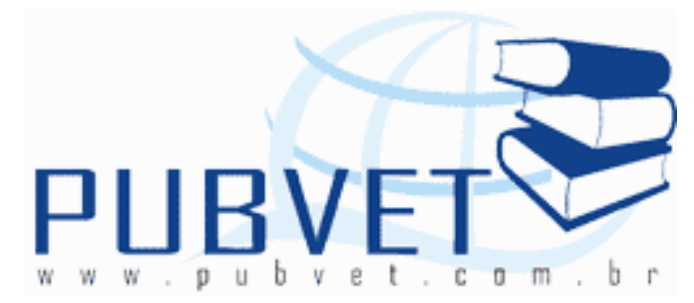

PUBVET, Publicações em Medicina Veterinária e Zootecnia.

\title{
Produção de carne de vitelo: sistemas produtivos e aspectos zootécnicos
}

Claudio Jonasson Mousquer ${ }^{1}$, Geferson Antonio Fernandes ${ }^{2}$,

Fabíola Francisca Dias Fernandes ${ }^{3}$, Verônica Bandeira Ferreira ${ }^{1}$, Larissa Alves Berté Barbosa ${ }^{1}$, Lucien Bissi da Freiria ${ }^{1}$, Mérik Rocha Silva ${ }^{1}$,

Wanderson José Rodrigues de Castro ${ }^{1}$

1 Mestrando em Ciência Animal - Universidade Federal de Mato Grosso, Campus de Cuiabá - MT

${ }^{2}$ Graduando em Zootecnia da Universidade Federal de Mato Grosso, Campus de Sinop - MT

${ }^{3}$ Medica Veterinária - Autônoma, Sinop - MT

\section{Resumo}

A pecuária brasileira de corte e de leite produz certa proporção de bezerros problemáticos, de baixo valor, aqueles considerados "fundo de boiada" e bezerros machos na produção leiteira, que poderiam ter melhor aproveitamento econômico. A utilização de machos leiteiros é bastante difundida e desenvolvida nos países Europeus, onde estes animais são utilizados para produção de carne e considerados uma importante fonte de renda para os produtores de leite e para a cadeia produtiva da carne. Os bezerros podem ser criados para a produção de vitelos de carne branca ou vitelos de carne rosa. Sendo esses últimos, apresentando maiores perspectivas 
de produção no Brasil, se tratando de aspectos humanitários da sua criação que isentam seus produtores de pressões de entidades ambientalistas e protetoras dos animais, como também pelo hábito alimentar da população, já que apresentam carne mais parecida com a dos bovinos adultos. Existe um mercado em potencial, mas ainda restrito, localizado principalmente próximos aos grandes centros. Desta forma, se torna interessante, criar alternativas baseadas em tecnologias adequadas às condições do país.

Palavras-chave: bezerro, desaleitamento, precocidade

\title{
Beef and veal production: production systems and zootechnic aspects
}

\begin{abstract}
The Brazilian cattle cutting and milk produces certain proportion of calves problematic, low value, those considered "bottom of cattle" and male calves in dairy production, which could have better economic use. The use of dairy bulls is widespread and developed in European countries, where these animals are used for meat production and are considered an important source of income for dairy farmers and the beef production chain. Calves can be reared for the production of veal calves white or pink meat veal. The latter being, with higher production prospects in Brazil, when dealing with humanitarian aspects of its creation that exempt the producers pressures of environmental organizations and animal protection, as well as the eating habits of the population, since they have more like meat of adult cattle. There is a potential market, but still limited, mainly located close to major centers. Thus, it becomes interesting, creating alternatives based on technologies appropriate to the conditions of the country.
\end{abstract}

Keywords: calf, weaning, precocity 
MOUSQUER, C.J. et al. Produção de carne de vitelo: sistemas produtivos e aspectos zootécnicos. PUBVET, Londrina, V. 7, N. 23, Ed. 246, Art. 1629, Dezembro, 2013.

\section{Introdução}

A demanda de carne bovina com qualidade no Brasil e no mercado mundial é crescente. Existe uma grande preocupação das pessoas com as elevadas taxas de colesterol no organismo o que tem levado ao consumo de carne bovina com menores índices de gordura. Essa possibilidade de atingir novos e promissores mercados, principalmente o internacional, depende, fundamentalmente, do empenho de todos os pecuaristas para rápida modernização dos sistemas de produção, aplicando as tecnologias disponíveis no Brasil e no Exterior, visando à produção de carne que atenda os padrões de qualidade e segurança alimentar.

Apesar de o Brasil ser detentor de um dos maiores rebanhos de bovinos do mundo, o seu volume de exportações ainda é inexpressivo, além de não atender de forma adequada a demanda interna (Ribeiro et al.,2001a). O mesmo autor ainda cita que entre os diversos fatores relacionados a este fato, destacam-se a baixa produtividade de seu rebanho, a falta de estímulo aos produtores, no sentido de uma remuneração condizente com os animais que apresentem melhores carcaças, além de problemas sanitários no rebanho.

Em alguns países, o aproveitamento dos bezerros de rebanhos leiteiros para a produção de carne é uma realidade, representando parcela significativa da carne consumida pela população. Um desses sistemas é a produção de vitelos, caracterizada pela alimentação dos animais exclusivamente com dieta líquida e produção de carcaças com carne branca e tenra. Os Vitelos podem ser obtidos de bezerros abatidos até 20 semanas de idade. Geralmente, esses animais são de origem leiteira, a maioria deles da raça Holandesa, alimentados exclusivamente com leite ou sucedâneos especiais do leite.

No Brasil, os bezerros da pecuária de leite são considerados um problema, uma vez que sua utilização na forma de produção de vitelos constitui atividade antieconômica para a realidade brasileira. Já na pecuária de corte os bezerros considerados como "fundo de boiada" acabam sendo um entrave para todo o sistema, principalmente quando se almeja uma produção 
MOUSQUER, C.J. et al. Produção de carne de vitelo: sistemas produtivos e aspectos zootécnicos. PUBVET, Londrina, V. 7, N. 23, Ed. 246, Art. 1629, Dezembro, 2013.

mais intensiva, com abate aos dois anos. Pelo fato de apresentarem ganho de peso reduzido, esses animais só poderão ser abatidos com mais de três anos de idade, com inferioridades na conversão alimentar e taxa de crescimento.

A viabilização da criação de bezerros para a produção de carne nos plantéis leiteiros especializados, principalmente os da raça Holandesa, tem sido ao longo da história da pecuária leiteira brasileira um desafio sempre presente (Caldas, 2003). Face às dificuldades impostas pelas elevadas exigências em nutrição, manejo e sanidade e altos custos de produção, a maioria dos produtores opta pelo seu descarte ao nascimento (Campos et al., 1996), sendo assim, desperdiçando uma possível renda complementar à atividade.

Segundo Medina et al., (2002) no concernente à alimentação, o leite apesar de ser o alimento ideal para qualquer mamífero em sua fase inicial de vida, torna-se proibitivo porque seu fornecimento aos bezerros implica em subtração da principal fonte de receita de uma propriedade leiteira. Por esse motivo, a adoção de sucedâneos lácteos em substituição total ou parcial ao leite torna-se fator de grande importância técnico-econômica.

Já Anderson et al. (1987) citado por Almeida Júnior, (2005) além da dieta líquida, os bezerros têm que ser estimulados o mais cedo possível a ingerirem alimentos concentrados já que este consumo é o fator mais importante para que o animal desenvolva precocemente o seu rúmen e respectiva flora microbiana, saindo da fase de pré-ruminante e passando a ruminante, de modo a permitir que o mesmo seja desaleitado precocemente.

O Brasil não tem tradição na produção de carne de vitelo; inclusive, o termo "vitelo" tem sido desprovido de identidade tanto para produtores quanto consumidores e é genericamente usado para descrever diversos tipos de animais abatidos jovens. Mesmo no Sistema Nacional de Tipificação de Carcaças Bovinas (Portaria 193/84), o vitelo é apenas descrito como o bovino (macho ou fêmea) abatido com até 12 meses (Almeida Júnior et al., 2008).

Na Europa, alguns países como Holanda, França, Itália e Alemanha têm muita tradição na produção e no consumo do vitelo tradicional e, de acordo com Ribeiro et al. (2001a), os sistemas normalmente utilizados incluem o 
vitelo de carne branca, animal criado com dieta líquida e abatido com 3 a 5 meses de idade pesando de 120 a $210 \mathrm{~kg}$, e o vitelo de carne rosa, animal desaleitado precocemente criado com dieta sólida com elevada proporção de grãos e abatido aos 5-6 meses com 225 a 250 kg PV.

O vitelo de carne rosa apresenta maiores potenciais de produção por apresentar menores custos de produção em comparação ao de carne branca, apresentar carne com características mais próximas da carne de bovinos consumida pela população e também por não sofrer pressões de ONGs ambientalistas e protetoras dos animais, que não aceitam as práticas de produção do vitelo de carne branca (Caldas, 2003).

A produção de vitelos pode ser uma boa forma para agregar valor principalmente aos pequenos produtores de leite, apresentando uma ótima fonte de renda secundária. A expectativa é que a demanda por este produto aumente em um futuro próximo, como resultado da estabilidade econômica e do aumento da renda per capta no Brasil. O mercado externo é outra possibilidade para comercialização que não deve ser ignorado.

A produção de vitelo no Brasil poderia favorecer maior giro de capital do investimento, através do abate precoce dos animais, entre 8 e 10 meses de idade, além de promover aumento de área de pastagem disponível para as matrizes e otimização da produção forrageira, através da redução do efetivo do rebanho (Ítalo et al., 2008).

O vitelo produzido pelos países Europeus é de carne branca ou rosa, sendo esta última para atender preferências de determinados mercados. Signoretti e Resende, (2005) Todavia, a carne branca responde por cerca de $90 \%$ da carne de vitelo comercializada no mercado interno europeu e no mercado externo, principalmente para o Japão e mais recentemente para China (grande mercado em expansão). Porém, aspectos relacionados com o sistema de criação definem o vitelo, e, por consequência, o preço. Deste modo, os valores pagos às carcaças de vitelos dependem principalmente de sua coloração. 
Como já mencionado, a coloração é um fator importante para a seleção de carne a ser consumida. Com isso, a cor de carne é fundamental na criação de vitelos e os preços podem variar de até $30 \%$ de acordo com sua tonalidade (Signoretti \& Resende, 2005). Contudo, em termos gerais, o preço dos cortes de carne de vitelos é superior ao de outros tipos de carne, o que afeta diretamente a difusão e o consumo de vitelo.

Existe um mercado em potencial, mas ainda restrito, localizado principalmente nos grandes centros (churrascarias especializadas, grandes redes de supermercados, açougues e frigoríficos habilitados para o abate). Desta forma, é interessante criar alternativas assentadas em bases tecnológicas adequadas às condições do país. Obviamente, esse sistema de produção deve ter preços diferenciados, o que daria bases para buscar alternativas no sentido de atuar sobre aqueles fatores que, de alguma forma, está influenciando negativamente o sistema de produção.

Considerando-se a disponibilidade de matéria-prima, bezerros oriundos das pecuárias de corte e/ou leite, e a expectativa de incremento na demanda por esse tipo de carne, há a necessidade de mais experimentos na área para avaliar o potencial de consumo desse tipo de carne. Para tanto, pesquisas tem que ser realizadas, utilizando questionários de avaliação sobre o préconhecimento e sobre a apreciação do produto, com o objetivo de avaliar o conhecimento das pessoas sobre o produto, a impressão e a disposição para aquisição da carne de vitelo por parte dos consumidores.

\section{Sistemas Produtivos e Aspectos Zootécnicos}

Uma das fases mais críticas na criação dos bezerros com predominância de sangue taurino é a fase inicial ou fase de aleitamento, seja pelo aspecto econômico (Teixeira et al., 1999) ou pelo aspecto técnico. E de acordo com Almeida Júnior, (2005) nesta fase são comuns os problemas advindos de má imunização por baixa ingestão de colostro ou exposição espoliativa a endo e 
MOUSQUER, C.J. et al. Produção de carne de vitelo: sistemas produtivos e aspectos zootécnicos. PUBVET, Londrina, V. 7, N. 23, Ed. 246, Art. 1629, Dezembro, 2013.

ectoparasitas, o que irá incorrer em elevados índices de morbidez e mortalidade.

Contudo, com o aumento da produtividade do rebanho leiteiro nacional por meio do melhoramento genético (Aroeira \& Paciullo, 2004), é de se esperar maior participação de animais com predominância de sangue europeu nos plantéis leiteiros brasileiros, o que exigirá a adoção de novas alternativas de criação para os bezerros nascidos nesses rebanhos, uma vez que são animais que não se adéquam aos sistemas extensivos tradicionais de criação de animais com predominância de sangue zebuíno.

Segundo Machado Neto et al., (2004) normalmente os machos, por não apresentarem 0 valor comercial das fêmeas nos rebanhos leiteiros especializados, são mais susceptíveis a problemas nessa fase por terem pouca ou nenhuma ingestão de colostro, o que aumenta excepcionalmente os riscos de doenças e mortalidade para os mesmos.

Embora exista informação técnica suficiente para a criação bem sucedida de bezerros de origem leiteira, a avaliação de alimentos que possam diminuir os custos de produção desses animais é fundamental para que se possa encontrar viabilidade econômica numa criação comercial de vitelos nas condições brasileiras de produção (Rodrigues Filho et al., 2002).

Nussio et al., (2003) destacaram a importância da ingestão de alimentos concentrados em bezerros, para que produzem na sua fermentação, principalmente os ácidos graxos voláteis (AGVs) propiônico e butírico, para o desenvolvimento de papilas ruminais em bezerros. Esses autores destacaram que dentre os principais AGVs produzidos no rúmen, o ácido butírico é o principal em relação ao crescimento em número e tamanho de papilas, seguido pelo ácido propiônico, tendo o ácido acético pouca importância.

A caracterização final do produto é um parâmetro fundamental para o consumidor no momento da compra, sendo um dos determinantes da frequência com que o produto será adquirido pelo mesmo. Muitos fatores podem influenciar as características de qualidade como: manejo pré e pós abate, sexo, idade, espécie, peso ao abate. Jorge et al., (2006) relataram que, 
para se assegurar a qualidade da carne, deve-se levar em consideração alguns fatores ante-mortem como: manejo, alimentação, sexo, idade, bem como post-mortem como: curva de queda de $\mathrm{pH}$ e temperatura. Esses fatores são de total relevância para se determinar outros parâmetros de qualidade, como cor, maciez e conservação da carne.

Quando visamos a carne in natura, a cor é o atributo mais observado na hora da compra (de primeiro momento), o odor é destacável durante o cozimento e a textura é mais importante no ato da mastigação da carne cozida. Porém, no aspecto de qualidade degustativa, a retenção de suco contribui para um produto cozido suculento, transmitindo uma sensação de prazer ao consumidor (Gonçalves \& Lemos, 2005).

No momento de degustação a maciez da carne é o fator primário que afeta a aceitabilidade do produto pelos consumidores. $O$ fato de a maciez ser 0 principal componente de satisfação do consumidor com relação à carne é facilmente confirmado pela positiva relação entre o preço dos cortes e a relativa maciez dos mesmos (Araújo, 2010). Os consumidores dão maior importância, no momento da compra da carne, à cor, gordura visível, ao preço e corte da carne.

Atualmente são classificados alguns sistemas de produção, que é caracterizado principalmente pela demanda do produto, mercado a ser explorado, facilidade pelo produtor no manuseio do determinado sistema e mão de obra. A saber: (i) produção de carne de vitelo de cor branca, (ii) produção de carne de vitelo de cor rósea, (iii) vitelão e, (iv) produção de vitelo em sistema orgânico.

\section{Produção de Carne Branca de Vitelo}

A produção de vitelo de carne branca tem como objetivo neste sistema obter bezerros com 115 a $200 \mathrm{~kg}$ de peso vivo (70 a $125 \mathrm{~kg}$ de carcaça), com aproximadamente, 3 a 4,5 meses de idade. Para tanto os bezerros precisam ganhar, em média, mais de $900 \mathrm{~g} /$ cabeça/dia, com boa conversão alimentar. A 
MOUSQUER, C.J. et al. Produção de carne de vitelo: sistemas produtivos e aspectos zootécnicos. PUBVET, Londrina, V. 7, N. 23, Ed. 246, Art. 1629, Dezembro, 2013.

carne dos animais deve apresentar uma coloração rosa pálida, e uma excelente textura, maciez e pouca gordura. O sistema de alimentação consiste em alojar os animais em baias individuais, e alimentá-los exclusivamente com dieta líquida, preferencialmente um substituto do leite, que deve ser deficiente em ferro.

Neste sistema a inclusão de concentrados ou volumosos poderá alterar a coloração da carne e inviabilizar a venda do produto. A cor clara da carne é, justamente, uma das principais preocupações durante o processo de produção, uma vez que este é o critério que define a qualidade e o preço no mercado. Ela também se caracteriza pela maciez e sabor brando, quando comparada a outros tipos de carne bovina. Signoretti \& Resende, (2005) traz citações que na Holanda esse sistema de produção de vitelo de carne branca inicia com um consumo de 125 a $200 \mathrm{~g}$ de substituto do leite para 1 a 2,5 litros de água e finaliza com 1400 a $1500 \mathrm{~g} /$ dia de substituto para 8,5 a 9 litros de água.

De acordo com o boletim da Embrapa Gado de Leite, (2007) a alimentação dos bezerros se baseia no fornecimento diário de quatro litros de colostro ou leite integral/animal durante as duas primeiras semanas de vida. A partir daí, a quantidade diária de leite é equivalente a 13,5\% do peso vivo do animal, ajustada a cada 15 dias (tabela 1). Do nascimento ao abate, são gastos, em média, 1.500 litros de dieta líquida por bezerro. Os animais atingem o peso ideal de abate (160 a $180 \mathrm{~kg}$ ) entre 16 a 20 semanas de vida.

Carvalho et al., (2003) avaliando composição física tecidual e residual da carcaça (quantidade osso, músculo e gordura) de bezerros machos de origem leiteira abatidos ao nascimento, 50 e 110 dias de idade, comprova que a proporção destes constituintes muda a medida que o animal se desenvolve, apresentando diferentes tendências de crescimento tecidual.

À medida que o animal cresce é sabido que, ocorre uma redução na proporção de osso e um incremento na proporção de músculo e gordura na carcaça. 
Tabela 1: Consumo médio de leite e peso vivo médio em diferentes semanas durante o processo de produção de vitelos na Estação Experimental de Itaguaí, da Pesagro-Rio, com animais mestiços Holandês-Zebu.

\begin{tabular}{ccc}
\hline $\begin{array}{c}\text { Período } \\
\text { (semanas) }\end{array}$ & $\begin{array}{c}\text { Consumo médio de leite } \\
\text { (kg/animal/dia) }\end{array}$ & $\begin{array}{c}\text { Peso vivo no final do } \\
\text { período } \\
(\mathbf{k g})\end{array}$ \\
\hline Nascimento & - & 33,5 \\
03 & 4 & 38,6 \\
$04-05$ & 6 & 46,3 \\
$06-07$ & 6,5 & 55,8 \\
$08-09$ & 8 & 68,5 \\
$10-11$ & 10 & 84,9 \\
$12-13$ & 12 & 100,2 \\
$14-15$ & 13,5 & 119,8 \\
$16-17$ & 16 & 136,4 \\
18 & 17 & 158,1 \\
$19-20$ & 17,5 & 167,1 \\
\hline
\end{tabular}

Fonte: Boletim Embrapa Gado de Leite, (2007). Juiz de Fora - MG.

Um Fator determinante para o sucesso da indústria de vitelos foi devido, principalmente, ao fato de as indústrias terem conseguido substituir a gordura do leite por outros tipos de gordura, quando da formulação dos sucedâneos (KEMPEN \& HUISMAN, 1991) citado por Alves \& Lizieire, (2001).

Nos sistemas de produção de vitelos, o custo final de produção depende, principalmente, do gasto com alimentação, normalmente elevado, tendo em vista que o leite integral ou sucedâneos especiais do leite constituem-se na única fonte de nutrientes para os animais (Alves e Lizieire, 2001).

Como no Brasil não há consumo expressivo de animais da categoria de vitelos de carne branca, em função de pouca ou nenhuma demanda de mercado, possivelmente em virtude de questões culturais, este fato acaba gerando uma escassez de trabalhos relacionados às características da carne desses animais, dificultando assim o estabelecimento de um padrão para tal produto (Araújo, 2010). Sendo, portanto, um campo vasto para pesquisa. 
MOUSQUER, C.J. et al. Produção de carne de vitelo: sistemas produtivos e aspectos zootécnicos. PUBVET, Londrina, V. 7, N. 23, Ed. 246, Art. 1629, Dezembro, 2013.

\section{Produção de Carne Rósea de Vitelo}

A carne rosada é produzida com bezerros de 5 a 6 meses de idade (Alguns autores citam em seus trabalhos até 7 meses), com um peso vivo de 225 a $250 \mathrm{~kg}$ ou $135-150 \mathrm{~kg}$ de carcaça. Para atingir este peso os animais precisam ganhar, em média, 1,2 kg por dia, com boa conversão alimentar. $\mathrm{O}$ sistema de alimentação é baseado no uso de substituto do leite durante as primeiras semanas de vida do bezerro, fazendo-se o desaleitamento o mais rápido possível, e utilizando-se então, um concentrado podendo ser fornecido à vontade, e pequenas quantidades de volumoso (Signoretti \& Resende, 2005).

Segundo Petit et al. (1991), os altos custos do leite ou de sucedâneos lácteos para criação de bezerros têm levado à necessidade do desenvolvimento de sistemas de produção de vitelos utilizando rações à base de grãos fornecidos ad libitum ou fracionados.

Rodrigues Filho et al. (2002) avaliaram os custos de produção de bezerros holandeses confinados até os $215 \mathrm{~kg}$ PV com diferentes níveis de concentrado e cama de frango e encontraram $o$ valores médio em porcentagens de custos para os itens alimentação e sanidade. Esses autores indicaram em ordem de importância no confinamento desses bezerros os itens: alimentação $(49 \%)$, bezerro (32\%), mão-de-obra (12\%), produtos veterinários $(1 \%)$, despesas diversas (6\%). Já Campos et al. (1996), analisando os custos de produção de bezerros holandeses abatidos aos $196 \mathrm{~kg}$ PV, encontraram aproximadamente $73 \%$ dos custos para alimentação, 10\% para bezerro, 10\% para medicamentos, $6 \%$ para mão-de-obra e $1 \%$ para outras despesas.

Ribeiro et al., (2001a) em seu trabalho, avaliou diferentes níveis de concentrado $(45,60,75,90)$ em substituição ao feno de coastcross (Cynodon dactylon (L.) Pers.) e, utilizando animais holandeses puros por cruza, abatidos ao completar $200 \mathrm{~kg}$, pode concluir que o nível de concentrado da dieta influenciou positivamente o rendimento de carcaça, sendo que os animais alimentados com dietas contendo $90 \%$ de concentrado apresentaram melhores rendimentos, além de maiores teores de gordura. E ainda o mesmo autor 
MOUSQUER, C.J. et al. Produção de carne de vitelo: sistemas produtivos e aspectos zootécnicos. PUBVET, Londrina, V. 7, N. 23, Ed. 246, Art. 1629, Dezembro, 2013.

ressalta que os resultados encontrados para o rendimento de carcaça, para todos os níveis de concentrado estudados, confirmam o potencial desses animais como produtores de carne, face ao seu ótimo desenvolvimento e à qualidade da carne produzida, indicando ser tecnicamente viável a possibilidade de exploração como produtores de carne.

Ribeiro et al., (2001b) em exploração de bezerros alimentados com concentrado (fubá de milho, farelo de soja, mistura mineral e calcário) em diferentes níveis (45, 60, 75 e 90) em substituição ao feno de capim-coastcross (Cynodon dactylon (L.) Pers.) fornecidos á vontade e sem tempo determinado. Os animais eram abatidos ao completarem $200 \mathrm{~kg}$ de peso vivo (PV).

Houve melhor utilização dos nutrientes da ração pelos animais, com a elevação dos níveis de concentrado, obtendo maiores ganhos $(0,96,1,04,1,13$ e 121), mostrando dessa maneira, que aqueles animais alimentados com $90 \%$ de concentrado utilizaram mais eficientemente a proteína e a fibra presentes nas rações em relação àqueles alimentados com $45 \%$ de concentrado.

De maneira geral, todos os animais apresentaram ótimo desenvolvimento em confinamento, para todos os níveis de concentrado estudados, indicando assim a viabilidade de criação desses animais neste sistema, conclui Ribeiro et al., (2001b).

O vitelo de carne rosa apresenta maiores potenciais de produção por apresentar menores custos de produção em comparação ao de carne branca, apresentar carne com características mais próximas da carne de bovinos consumida pela população e também por não sofrer pressões de ONGs ambientalistas e protetoras dos animais, que não aceitam as práticas de produção do vitelo de carne branca (Caldas, 2003).

A silagem de grãos úmidos inteiros de sorgo apresenta menor custo de produção por dispensar a operação da moagem, assim, seu uso pode trazer vantagens econômicas (Almeida Júnior et al., 2008), podendo ser usado em rações para bezerros holandeses após o desaleitamento, pois não prejudicam o desempenho do animal e conferem os mesmos resultados obtidos com o milho 
MOUSQUER, C.J. et al. Produção de carne de vitelo: sistemas produtivos e aspectos zootécnicos. PUBVET, Londrina, V. 7, N. 23, Ed. 246, Art. 1629, Dezembro, 2013.

seco moído e, em muitos casos tendo impacto econômico positivo sobre o sistema de criação de vitelos de carne rosa.

\section{Produção de Carne de Vitelão}

Se por um lado a produção de vitelos apresenta-se com restrições em virtude do custo de produção e da demanda reprimida, a disponibilidade de bezerros considerados problemáticos, tanto na pecuária leiteira como na de corte, clama soluções para sua melhor exploração. Como alternativa para agregar valor a esses animais tem-se a possibilidade de abatê-los perto dos doze meses de idade, com a finalidade de produção de uma carne diferenciada.

Por causa das características desses animais não se pode defini-los como vitelos e tampouco como novilhos; nesse caso, propõe-se denominá-los de "vitelão".

Os vitelões são animais desmamados aos três meses ou até mesmo ao 6 meses e abatidos aos sete - doze meses com peso vivo em torno de 280-330 $\mathrm{kg}$. O que diferencia o vitelão do vitelo é a idade de abate e a alimentação recebida. O vitelão é aquele animal recém-desmamado que recebeu alimentação sólida e foi abatido com até doze meses de idade (Feijó et al., 2001).

Logo, o vitelão seriam considerados todos os bovinos machos, castrados ou não, e fêmeas com idade inferior aos doze meses por ocasião do abate. Aspectos como maciez e reduzido valor calórico são características esperadas para a carne de vitelão, uma vez que ela é oriunda de animais jovens com reduzida deposição de gordura.

De acordo com Feijó et al., (2001) para o criador, as vantagens são grandes, já que tem um animal abatido superprecocemente, possibilitando a liberação da vaca mais rapidamente, facilitando a sua recuperação para a gestação futura, trabalhando dentro de um mercado especializado. 
A carne de vitelão é atrativa aos consumidores e a maciez é a principal característica organoléptica da carne de vitelão. A carne, uma vez identificada como vitelão, tem possibilidade de ser explorada como substituta parcial da carne bovina usualmente consumida.

Mesmo associada à carne de vitelo, o vitelão preserva seu caráter de "novidade", uma vez que a primeira é produto pouco consumido no Brasil. Assim, essa condição de inovação pode ser também explorada em campanhas promocionais no Brasil.

O vitelão apresenta maiores perspectivas de produção no Brasil, tanto pelos aspectos humanitários da sua criação que isentam seus produtores de pressões de entidades ambientalistas e protetoras dos animais, quanto pelo hábito alimentar da população, já que apresentam a carne mais parecidas com a dos bovinos adultos, alem de apresentar menores custos comparativos de produção (Caldas, 2003).

\section{Produção de Carne de Vitelão em Sistema Orgânico}

Atualmente após a "modernização" do setor agropecuário, a pecuária de corte caracteriza-se como qualificada e competitiva, embora de baixa rentabilidade, alicerçada pela pesquisa, no processo de qualificação de profissionais do mercado e na segmentação da produção e do consumo (Alves, 2005; Polaquini, 2006).

Em observação á essa mudança, ocorre mudanças na cadeia da pecuária de corte como a diferenciação de produtos, a otimização dos custos, a incorporação de sistemas de rastreabilidade, a instituição de programas de certificação de origem e produção, a criação de selos de qualidade e marcas, entre outras (Polaquini, 2006). Consequentemente, o interesse dos consumidores pelo modo com 0 qual os alimentos são produzidos e a disponibilidade de pagar mais por produtos diferenciados, cresceu (Alves, 2007). 
MOUSQUER, C.J. et al. Produção de carne de vitelo: sistemas produtivos e aspectos zootécnicos. PUBVET, Londrina, V. 7, N. 23, Ed. 246, Art. 1629, Dezembro, 2013.

Mundialmente existe mais de 100 diferentes sistemas de certificadores orgânicos, sendo os de padrões internacionais aquele de maior importância: Regulamento da União Européia (EU Organic Directive Regulation), padrões básicos da IFOAM e o guia produzido em 1999 pela comissão da Codex Alimentarius da food and Agriculture Organization (FAO) e Organização Mundial de Saúde (OMS) (Neves, 2002).

Os produtos orgânicos de origem animal têm uma estória mais recente quando comparados aqueles de origem vegetal, visto a complexidade e maior duração do ciclo de produção. A primeira fazenda orgânica de cria no país foi certificada em 1999 (Faz. Eldorado-MS - Instituto Biodinâmico), sendo que, em 2000, foi realizada a primeira exportação de carne orgânica, pelo Frigorífico Independência, á comunidade Européia (Alves, 2007).

Atualmente Somente Mato Grosso e Mato Grosso do Sul, produzem carne orgânica certificada no país. São 13 fazendas e 70 mil hectares em pastagens, com 55 mil reses certificadas pelo Instituto Biodinâmico (IBD) (Alves, 2007).

O sistema pecuário de produção orgânica foi descrito por Haddad e Castro, (2004) que sua aplicabilidade seria mais lucrativa em regiões como o Pantanal, Ilha do Marajó e Pampas Gaúchos, pois resulta particularmente funcional aos processos de desenvolvimento rural em áreas marginais, enquanto capaz de valorizar as potencialidades locais não utilizáveis ou utilizáveis menos eficiente.

Entre os princípios a serem seguidos na pecuária orgânica certificada, destaca-se o bem estar animal, o fornecimento de alimentos adequados as características fisiológicas inerentes á cada espécie, a manutenção da saúde animal através de práticas de manejo preventivas, onde o uso de alopatias profiláticas deve ser evitado, dando-se preferência a homeopatia e outros regimes terapêuticos alternativos (Haddad e Castro, 2004).

De acordo com o Pacheco, (2012) a fazenda para entrar no programa de produção de carne orgânica, alguns critérios devem ser avaliados com: A vegetação nativa em encosta, morros e as margens do rio, a conservação do solo, a regularização fundiária e ambiental, controle de fogo, poluição e 
MOUSQUER, C.J. et al. Produção de carne de vitelo: sistemas produtivos e aspectos zootécnicos. PUBVET, Londrina, V. 7, N. 23, Ed. 246, Art. 1629, Dezembro, 2013.

segurança no trabalho. Haddad e Castro, (2004) ainda destaca a utilização de fitoquímicos e hormônios nos animais.

Algumas iniciativas surgiram em nível nacional, como o "Vitelo Pantaneiro" (VITPAN), também chamado de "Vitelo Orgânico do Pantanal", certificado pela ECOCERT. Trata-se de animal Nelore ou azebuzado, abatido entre 8 e 12 meses, com 180 a 230 kg PV, criado de maneira extensiva e dentro das normas do Sistema de Produção Orgânico (Feijó et al., 2001).

\section{Considerações Finais}

Se considerarmos o tamanho do rebanho leiteiro nacional, o forte apelo comercial da carne brasileira ("boi verde", criado a pasto) e os custos de produção extremamente competitivos em relação aos custos praticados na Europa e nos Estados Unidos, o Brasil apresenta-se como potencial fornecedor mundial de carne de vitelão e vitelo, tanto de coloração branca como rósea.

Observa-se ainda que o crescimento do setor orgânico no Brasil não foi acompanhado de um adequado desenvolvimento da pesquisa, haja vista que, apesar da demanda por sistemas de produção alternativos e diversificados, existe ainda uma crônica carência de dados e referências experimentais.

As restrições impostas pelo sistema orgânico, principalmente em relação ao plano nutricional, podem comprometer o crescimento e, consequentemente, parâmetros importantes como peso de abate e grau de acabamento.

\section{Referências Bibliográficas}

ALMEIDA JÚNIOR, G. A.; COSTA, C.; CARVALHO, S. M. R.; PERSICHETTI JÚNIOR, P.; PANICHI, A. Desempenho de bezerros holandeses alimentados após o desaleitamento com silagem de grãos úmidos ou grãos secos de milho ou sorgo. Revista Brasileira de Zootecnia, v.37, n.1, p.148-156, 2008.

ALMEIDA JÚNiOR, G. A. Produção de Vitelos de Carne Rosa com Bezerros Holandeses. Botucatu - SP: UNESP, 2005. 115 p. (Tese de Doutorado).

ALVES, D. D. Maciez da carne bovina. Ciência Animal Brasileira, Goiânia, v.6, n.3, p. 135$149,2005$. 
ALVES, F. V. Desempenho e características físico-químicas da carne de vitelões Nelore e Limousin $x$ Nelore criados sob sistema orgânico e submetidos a diferentes suplementações em cocho privativo. Piracicaba - SP: ESALQ/USP, 2007. 112p. (Tese de Doutorado).

ALVES, P. A. M.; LIZIEIRE, R. S. Teste de um sucedâneo na produção de vitelos. Revista Brasileira de Zootecnia, v.30, n.3, p.817-823, 2001.

ARAÚJO, L. L. S. Atributos sensoriais da carne de bezerros mestiços abatidos aos 60 dias de idade. Mossoró - RN: UFERSA, 2010. 40 p. (Dissertação de Mestrado).

AROEIRA, L. J. M.; PACCIULLO, D. S. C. Produção de leite a pasto. Informe Agropecuário, v.25, n.221, p.56-63, 2004.

CALDAS, F. Vitelo: opção de ganho na exploração leiteira. Revista Balde Branco. v.38, n.461, p.36-40, 2003.

CAMPOS, O. F.; LIZIEIRE, R. S.; SPALLA, R. G. et al. Experimento do CNPGL/EMBRAPA com abate de machinhos da raça holandesa aos 6 meses de idade apresenta bons resultados. Gado Holandês, v.451, p.36-45, 1996.

EMPRESA BRASILEIRA DE PESQUISA AGROPECUÁRIA - EMBRAPA. [2007]. Produção de Vitelos. Disponível em: www.cnpgl.embrapa.br/divulgação/artigos.htm Acesso em: $01 / 06 / 2012$.

FEIJÓ, G. L. D.; COSTA, F. P.; FEIJÓ, R. M. B. Carne de vitelão: Estudo exploratório de um mercado potencial. Campo Grande: Embrapa, 2001. 20 p. (Série Documentos / Embrapa Gado de Corte, ISSN 1517-3747; 105).

GONÇALVES, J. R.; LEMOS, A. L. S. C. Efeitos do grau de cozimento na qualidade de cortes de Supraspinatus acondicionado a vácuo em embalagem cook-in. Ciência e Tecnologia de Alimentos. Campinas. v. 25, n .2, 2005.

HADDAD, C. M.; CASTRO, F. G. F. Sistema de produção de carne orgânica no Pantanal. In: MATTOS, W. R. S. (Ed) A produção animal na visão dos brasileiros. Piracicaba: FEALQ, 2001. P. 302-326.

ÍTALO, L. C. V.; OLIVEIRA, N. P. R.; ÍTALO, C. C. B. F.; SILVA, M. J.; DiAS, A. M.; GOMES, R. C. Produção de bezerros jovens em pastagens nativas, mistas ou cultivadas no Pantanal Sul Mato-Grossense. Revista Brasileira de Saúde e Produção Animal, v.9, n.3, p.585-593, 2008.

JORGE, A. M; ANDRIGHETTO, C; MILLEN, D. D. et al. Características bioquímicas da carne de bubalinos Mediterrâneo terminados em confinamento e abatidos em diferentes pesos. Ciência Rural. Santa Maria, v.36, n.5, p.1534-1539, 2006.

KEMPEN, G.J.M. van, HUISMAN, J. Introductory remarks: some aspects of skim-milk replacement by other protein sources in veal-calf diet. In: NEW TRENDS IN VEAL CALF PRODUCTION, 1991, Wageningem. Proceedings.... Wageningen, Netherlands, p.201-205, 1991.

MACHADO NETO, R.; CASSOLI, L. D.; BESSI, R. et al. Avaliação do fornecimento adicional de colostro para bezerros. Revista Brasileira de Zootecnia, v.33, n.2, p.420-425, 2004. 
MEDINA, R. B.; LÜDER, W. E.; FISCHER, V. et al. Desaleitamento precoce de terneiros da raça holandês preto e branco utilizando sucedâneo do leite ou leite e concentrado farelado ou peletizado. Revista Brasileira de Agrociência, v.8, n.1, p.61-65, 2002.

NEVES, M. C. P. Por que não utilizar ureia como fonte de $\mathrm{N}$ na agricultura orgânica. Cadernos de Ciência e Tecnologia, Brasília, v.9, p. 313-331, 2002.

NUSSIO, C. M. B.; SANTOS, F. A. P.; ZOPOLLATTO, M. et al. Parâmetros de fermentação e medidas morfométricas dos compartimentos ruminais de bezerros leiteiros suplementados com milho processado (floculado vs. laminado a vapor) e monensina. Revista Brasileira de Zootecnia, v.32, n.4, p.1021-1031, 2003.

PACHECO, L. P. A. 15 anos Boi Verde. Noticiário TORTUGA. Edição 478, ano.56, 82p. 2012.

PETIT, H. V.; LACHANCE, B.; DIORIO, D. The effect of protein source on the growth and carcass characteristics of veal calves. Canadian Journal of Animal Science, Otawa, v.71, n.2, p.409-416, 1991.

POLAQUINI, L. E. M. Transformações técnico-produtivas e comerciais na pecuária de corte brasileira a partir da década de 90. Revista Brasileira de Zootecnia, Viçosa, v.35, n.1, p. 321-327, 2006.

RIBEIRO, T. R.; PEREIRA, J. C.; OliVeirA, M. V. M.; QUEIROZ, A. C.; CECON, P. R.; LEÃO, M. I.; MELO, R. C. A. Características da carcaça de bezerros holandeses para produção de vitelos recebendo dietas com diferentes níveis de concentrado. Revista Brasileira de Zootecnia, v.30 n.6 (suplemento), p.2154-2162, 2001 a.

RIBEIRO, T. R.; PEREIRA, J. C.; OLIVEIRA, M. V. M.; QUEIROZ, A. C.; CECON, P. R.; LEÃO, M. I.; MELO, R. C. A. Influência do plano nutricional sobre o desempenho de bezerros holandeses para a produção de vitelos. Revista Brasileira de Zootecnia, v.30, n.6 (suplemento), 21452153, 2001b.

RODRIGUES FILHO, M.; MANCIO, A. B.; GOMES, S. T. et al. Avaliação econômica do confinamento de novilhos de origem leiteira, alimentados com diferentes níveis de concentrado e de cama de frango. Revista Brasileira de Zootecnia, v.31, n.5, p.2055-2069, 2002.

SIGNORETTI, R. D.; RESENDE, F. D. Vitelo: Sistema de produção de carne de vitelo. Pesquisa \& Tecnologia, vol.2, n.2, 2005. Disponível em: www.aptaregional.sp.gov.br/artigos. Acesso em: 01/06/2012.

TEIXEIRA, J.C.; SANTOS, R.M.; PEREZ, J.R.O. et al. Aproveitamento do macho leiteiro utilizando dietas à base de amiréia 45S. I Biometria do trato gastrointestinal e características de carcaça. Ciência e Agrotecnologia, v.23, n.2. p.421-426, 1999. 